\title{
Evaluating the Effectiveness of Onboard Video Feedback Systems on Reducing Transit Collisions and Injuries
}

Michael Litschi and Peter Haas, Ph.D.

Mineta Transportation Institute, San Jose State University

\begin{abstract}
In the mid-2000s, public transit agencies began testing onboard video feedback systems on buses, which capture short video clips when triggered by an unusual event such as hard braking, a sharp turn, or impact with an object. The objective of this study was to determine whether the systems have enhanced passenger safety by reducing the frequency and severity of collisions and injuries and to identify lessons learned from the implementation of such systems. The study concludes that the systems appear to have a positive impact on transit safety achieved through a reduction in collisions and injuries and the risky driving behaviors that contribute to them. The systems provide transit mangers with a wealth of information about their employees' driving habits that was not previously available. Transit agencies should consider investing in such systems as one component of an overall safety and training program.
\end{abstract}

\section{Introduction}

In the mid-2000s, a handful of public transit agencies in the United States began installing video feedback systems in buses specifically intended to improve transit operator safety and adherence to safety regulations. Although this technology has been used on commercial fleet vehicles for a number of years, its application in the public transit industry is still relatively recent. Proponents of the systems argue that they provide feedback that helps identify potentially dangerous driving behavior before it leads to a collision or injury. Such feedback also serves to deter operators from violating transit-specific safety regulations such as bans on use of personal electronic devices. Manufacturers of the video systems claim they can lead to significant reductions in the frequency and severity of crashes, as well as the number of worker compensation and personal injury claims (DriveCam 2011).

However, the video feedback systems also have prompted objections from union officials, and transit operators themselves, who believe they constitute an invasion of privacy and are not a cost-effective solution to improve transit safety. Such feedback has been shown to lead to significant reductions in safety-relevant events in young drivers and commercial 
over-the-road truckers (Carney et al. 2010; McGehee et al. 2007; Hanowski et al. 2010). To date, there have been no formal studies examining the effectiveness of these types of systems on improving safety in the transit industry through a reduction of safety-related events and the frequency and severity of crashes and injuries.

There are currently two primary companies that manufacture video-based driver feedback systems used by transit operators: DriveCam, Inc. (now Lytx, Inc.) and and SmartDrive Systems, Inc., both based in San Diego, California. This research project evaluates the effectiveness of the DriveCam system used by six public transit operators and three private contractors and develops lessons learned in implementing the system. The Los Angeles County Metropolitan Transportation Authority's (Metro) experience with the SmartDrive system also is discussed. In addition, after the research period was complete, Veolia switched its video system provider from DriveCam to SmartDrive. DriveCam and SmartDrive both are used by trucking firms, private motorcoaches, taxi cabs, and a wide variety of other fleet vehicles; however, this study focuses specifically on use of the systems in transit buses. Similar systems also are in limited use on transit buses in Europe and South Africa, although their effectiveness has yet to be examined in published research.

Although several past research studies have explored the impact of using behavior-based techniques, including video recording devices, to improve safety in the trucking and motorcoach industries, there have been no published reports regarding the use of such technology in the U.S. public transit industry. This study examines whether the systems have been successful in enhancing safety in the transit industry by reducing the frequency and severity of collisions and injuries.

\section{Background and Literature Review}

The video-based driver feedback systems currently used by transit industry clients use a small, palm-sized dual-lens video camera that is mounted on the vehicle windshield, usually behind the interior rear-view mirror of the bus. A wide-angle camera captures the view out the front windshield of the bus; an interior view, including a clear view of the operator; and, typically, the farebox and at least a portion of the passenger seating area. The cameras also include a microphone to capture audio inside and outside the vehicle.

Although the cameras are always on during operation, the system is set to save short (1215 second) video clips only when triggered by gravitational forces ( $g$-forces) that approximate about $0.5 \mathrm{~g}$, such as sudden braking or acceleration, swerving, sharp turns, or the impact of a collision. The camera systems automatically save video footage from before and after a triggered event. Transit clients using the DriveCam system receive video clips of 8 seconds before and 4 seconds after each triggered event. If the driver operates the vehicle in a safe manner, the system never records an event. The transit operator also can press a button to manually trigger a clip to be saved if there is a particular event he or she wants recorded.

\section{Role of Video Feedback in Behavior-Based Safety}

A 2003 Transportation Research Board (TRB) report discusses the recommended use of behavior-based safety techniques to improve safety in the trucking and private motorcoach industry, including on-board video systems (Knipling et al. 2003). The report 
defines behavior-based safety as "a set of methods to improve safety performance by teaching workers to identify critical safety behaviors, perform observations to gather data, provide feedback to each other to encourage improvement, and use gathered data to target system factors for positive change" (Knipling et al. 2003, 27). It found that behavior-based safety has been used successfully for decades in industrial settings to reduce risky behaviors, encourage safe behaviors, and prevent occupational injuries and compensation claims (Knipling et al. 2003). Studies also show safety benefits when behavior-based safety techniques are used in the trucking and motorcoach industries, where it is much more difficult to conduct direct behavioral observation and feedback (Hanowski and Hickman 2010).

Truck drivers, motorcoach drivers, and transit operators generally operate their vehicles independently. It is difficult and cost-prohibitive for managers to provide direct, real-time supervision of all drivers in the field, unlike in the manufacturing industry, in which many workers are based in the same location and their activities can be viewed by management. As a result, transit operators resemble "street-level bureaucrats," which have frequent, direct interaction with the public, but enjoy a relatively high degree of independence in their work due to the difficulty of providing direct supervision (Lipsky 1980).

The TRB report also discusses the use of electronic feedback systems as a safety tool in the trucking and motorcoach industries. Video feedback provides critical context and goes far beyond the ubiquitous "How's my driving?" placard. It is not reliant on the potentially-biased testimony of other drivers, and this can help exonerate drivers who have done nothing wrong. On-board video systems also eliminate the subjectivity of relying on other drivers or, in the case of the transit industry, passengers to report unsafe driving behavior.

Penn + Schoen Associates (1995) found that commercial drivers were skeptical of new technology that could be perceived as an invasion of privacy or as diminishing the role of driver judgment. Their study also showed that on-board monitoring was the least-accepted technology by the drivers, even though they generally acknowledged its potential safety benefits. However, the study looked at continuous monitoring, which is more invasive than the video-based driver feedback systems that are the subject of this paper, and there has been a cultural shift in perceptions of privacy since 1995, particularly with the advent of social media. Hickman and Geller (2002) found that instructing short-haul truck drivers to use self-management strategies to monitor their driving behavior resulted in significant decreases in at-risk driving behaviors such as hard braking and speeding.

The authors of the TRB study conclude that "[On-Board Safety Monitoring] technology and behavioral applications are underused in truck and bus transport in relation to their safety potential," and that the technology should be used in safety training programs to demonstrate that unwanted driving behaviors that are likely to increase the likelihood of a crash (Knipling et al. 2003, 45).

\section{Effectiveness of Video-Based Driver Feedback Systems}

Although there have been no formal studies to date examining the effectiveness of video-based driver feedback systems on improving safety in the transit industry, at least one formal study has examined the technology's impact on safety in the trucking industry. In April 2010, the Federal Motor Carrier Safety Administration (FMCSA) funded a study that 
conducted an independent evaluation of the DriveCam system at two private trucking firms (Hanowski and Hickman 2010).

The study found that participating drivers at the two firms reduced the mean frequency of recorded safety-related events per 10,000 vehicle miles traveled by 37 percent and 52.2 percent, respectively, during a 13-week "intervention" after implementation of DriveCam, compared to a four-week "baseline" phase before the system was in place. Although installation of the DriveCam system alone provided safety benefits, the recommended coaching program improved the results even further. "The coaching sessions where drivers reviewed a video of a safety-related event resulted in significant safety benefits, whereas the feedback light alone and/or coaching sessions without videos were less robust" (Hanowski and Hickman 2010, 34). The authors of the study concluded that, "Safety benefits on the scale found in this study highlight the potential for [video-based driver feedback systems] to have a robust impact in reducing truck crashes on our nation's highways" (Hanowski and Hickman 2010, 34).

In 2009, Loomis Armored conducted a six-month pilot study of the SmartDrive system involving more than 2,800 drivers and more than 1,000 vehicles. Loomis experienced a 53 percent reduction in collision frequency during the pilot program and reported "significant per-driver improvements across four important metrics that are leading factors in collisions" (Trucks at Work 2009, 1). Distracted driving dropped 54 percent, fatigue behind the wheel dropped 56 percent, non-use of seatbelts dropped 68 percent, and speeding dropped 53 percent (Trucks at Work 2009).

Finally, 2007 and 2010 studies by the University of lowa examined the impact of installing the DriveCam system in the cars of newly-licensed drivers. The DriveCam equipment used in the studies was similar, but not identical, to that used in transit buses. The studies found a significant reduction in the number of safety-relevant events, with drivers reducing their rate of safety-related events from an average of 8.6 events per 1,000 miles during the baseline phase to 3.6 events per 1,000 miles, or approximately 58 percent during the intervention phase. The group further reduced its rate of safety-related events to 2.1 per 1,000 miles in the following nine weeks (weeks 10-18), achieving a 76 percent reduction from the baseline. Among the riskiest drivers, safety-relevant events were reduced by 88 percent. The studies' authors concluded that an event-triggered video system, paired with feedback in the form of a weekly graphical report card and video review, can result in a significant decrease in unsafe driving behaviors (McGehee et al. 2007; Carney et al 2010.).

Overall, the published research to date indicates that video-based driver feedback systems generally have proven effective at reducing risky driving behaviors where they have been implemented-risky driver behaviors that often can lead to collisions. However, these studies have included only a few hundred drivers, so measuring crash and injury reduction is difficult to do with such small $\mathrm{N}$ studies. Safety-relevant events provide the best estimates to evaluate such technologies. Driving in over-the-road trucking and passenger vehicles is different when compared to transit buses, in which bus drivers make frequent stops and also must interact with passengers. 


\section{Methodology}

This study synthesizes data from the U.S. transit agencies currently using video-based driver feedback systems to determine if there is a pattern that indicates that the cameras are an effective tool to enhance safety by preventing risky driving behaviors and, in turn, reducing the frequency and severity of collisions and injuries. The two primary data sources used to evaluate effectiveness are National Transit Database (NTD) crash and injury statistics and qualitative results reported directly by transit operators in interviews.

NTD crash and injury statistics were examined for each of the six public transit operators using the DriveCam system through calendar year 2012 to look for any trends in the safety performance of directly-operated bus services that could be correlated with adoption of video-based driver feedback systems. Due to the complexity of tracking which of the firms' transit clients were using DriveCam and on which portion of the fleet during a particular time period, however, NTD data were not analyzed for the three contracted operators using DriveCam - First Transit, MV Transportation, and Veolia Transportation. This information is summarized in Tables 1 and 2.

\section{TABLE 1.}

Transit Agencies with at Least Two Years of Published Safety Data Post-Implementation

\begin{tabular}{|c|c|c|c|}
\hline $\begin{array}{c}\text { Transit } \\
\text { Agency }\end{array}$ & $\begin{array}{l}\text { Average Change in Frequency of } \\
\text { Collisions, Passenger Injuries After } \\
\text { Implementation Compared to Four Years } \\
\text { Before Implementation per NTD Data }\end{array}$ & $\begin{array}{c}\text { Results Reported by Transit Agency } \\
\text { Managers Interviewed }\end{array}$ & Implementation Notes \\
\hline $\begin{array}{l}\text { Capital } \\
\text { Metro }\end{array}$ & $\begin{array}{l}\text { Yes/no; } 15 \% \text { reduction in passenger injuries } \\
\text { in } 5 \text { years after implementation of DriveCam } \\
\text { in 2007; number of collisions increased by } \\
4 \% .\end{array}$ & $\begin{array}{l}\text { Noticeable reduction in frequency of } \\
\text { scored events, number of rule violations, } \\
\text { and severity of collisions, but no clear } \\
\text { reduction in collision frequency. }\end{array}$ & $\begin{array}{l}\text { Use DriveCam to incentivize "event- } \\
\text { free" driving; provide continuing } \\
\text { education on how to improve driving. }\end{array}$ \\
\hline $\begin{array}{l}\text { LA } \\
\text { Metro }\end{array}$ & $\begin{array}{l}\text { Yes; } 19 \% \text { reduction in collisions, } 36 \% \\
\text { reduction in injuries in } 3 \text { years since } \\
\text { SmartDrive installed in } 2009 .\end{array}$ & $\begin{array}{l}30 \% \text { reduction in "events with safety } \\
\text { concern" in } 1 \text { st year of program. }\end{array}$ & $\begin{array}{l}\text { Ensure bus operators understand } \\
\text { that intent of system is training, not } \\
\text { discipline. }\end{array}$ \\
\hline $\begin{array}{l}\text { New } \\
\text { Jersey } \\
\text { Transit }\end{array}$ & $\begin{array}{l}\text { Yes; } 68.5 \% \text { reduction in collisions and } 57 \% \\
\text { reduction in injuries over } 5 \text { years since } \\
\text { DriveCam installed in } 2007 \text {. }\end{array}$ & $\begin{array}{l}\text { "Significant" decrease in scored events; } \\
\text { noticeable reduction in "egregious" safety } \\
\text { violations. }\end{array}$ & $\begin{array}{l}\text { Program not as effective if } 100 \% \text { of fleet } \\
\text { not equipped with DriveCam. }\end{array}$ \\
\hline $\begin{array}{l}\text { Pace } \\
\text { Bus }\end{array}$ & $\begin{array}{l}\text { Yes/no; } 20 \text { reduction in collisions, } 23 \% \\
\text { increase in passenger injuries in } 2 \text { years since } \\
\text { implementation in } 2010 .\end{array}$ & $\begin{array}{l}\text { "Dramatic decrease" in number and } \\
\text { frequency of risky driving behaviors; } \\
\text { useful in combating fraudulent claims. }\end{array}$ & $\begin{array}{l}\text { Use incentives to recognize safe, } \\
\text { defensive driving coupled with timely } \\
\text { coaching. }\end{array}$ \\
\hline SFMTA & $\begin{array}{l}\text { Yes; } 28 \% \text { reduction in collisions and } 44 \% \\
\text { decrease in injuries over } 3 \text { years since } \\
\text { DriveCam installed in } 2009 .\end{array}$ & $\begin{array}{l}33 \% \text { reduction in scored events and } 35 \% \\
\text { decrease in severity of incidents after } 10 \\
\text { months. }\end{array}$ & $\begin{array}{l}\text { Using DriveCam in coordination with } \\
\text { progressive discipline policy is key to } \\
\text { seeing fewer incidents. }\end{array}$ \\
\hline WMATA & $\begin{array}{l}\text { No. } 19 \% \text { increase in collisions and } 21 \% \\
\text { increase in passenger injuries in } 2 \text { years since } \\
\text { DriveCam installed in } 2010 .\end{array}$ & $\begin{array}{l}23 \% \text { reduction in frequency and } 25 \% \\
\text { reduction in severity of scored events } \\
\text { after } 6 \text { months. }\end{array}$ & $\begin{array}{l}\text { Timely training/coaching key to seeing } \\
\text { results; should combine progressive } \\
\text { discipline with recognition of good } \\
\text { driving. }\end{array}$ \\
\hline
\end{tabular}


TABLE 2.

Contracted Operators without Safety Data Available for Analysis

\begin{tabular}{|l|l|l|l|}
\hline Transit Agency & $\begin{array}{c}\text { Average Change in Frequency of } \\
\text { Collisions, Passenger Injuries After } \\
\text { Implementation Compared to Four Years } \\
\text { Before Implementation per NTD Data }\end{array}$ & $\begin{array}{c}\text { Results Reported by Transit Agency } \\
\text { Managers Interviewed }\end{array}$ & \multicolumn{1}{|c|}{ Implementation Notes } \\
\hline First Transit & $\begin{array}{l}\text { N/A; NTD data not analyzed due to multiple } \\
\text { transit clients. }\end{array}$ & $\begin{array}{l}50 \% \text { reduction in scored events; } \\
\text { reduction in collision frequency from } \\
10 \text { per million vehicle revenue miles to } \\
6 . \text { Began using DriveCam in 2006. }\end{array}$ & $\begin{array}{l}\text { Ensure management team prepared } \\
\text { to monitor wealth of information } \\
\text { DriveCam provides and take } \\
\text { appropriate action. }\end{array}$ \\
\hline MV & $\begin{array}{l}\text { N/A; NTD data not analyzed due to multiple } \\
\text { transit clients. }\end{array}$ & $\begin{array}{l}30-40 \% \text { reduction in collisions. Began } \\
\text { using DriveCam in 2004. }\end{array}$ & $\begin{array}{l}\text { Managers should use DriveCam to } \\
\text { observe and correct risky driving } \\
\text { behaviors before they lead to a crash. }\end{array}$ \\
\hline Veolia & $\begin{array}{l}\text { N/A; NTD data not analyzed due to multiple } \\
\text { transit clients. }\end{array}$ & $\begin{array}{l}\text { "Clear decrease" in crash frequency } \\
\text { and severity." Began using DriveCam } \\
\text { in 2004, switched to SmartDrive in } \\
2011 .\end{array}$ & $\begin{array}{l}\text { Need to tie motivational program } \\
\text { for good driving with disciplinary } \\
\text { component for risky driving. }\end{array}$ \\
\hline
\end{tabular}

NTD safety data for each transit client are segregated into two groups: Directly-Operated and Purchased transportation. Because some transit agencies use multiple contract operators to provide service under the Purchased transportation category, NTD data could not be used to track the effectiveness of the systems being used on contracted services. Finally, data tracking the number of monthly scored events and collisions per event recorder were obtained from DriveCam, Inc., for its transit-industry clients to analyze safety trends following the launch of the DriveCam system.

Supplemental information was gathered through phone interviews with managers at each transit agency. Some agencies provided specific metrics on results experienced since implementation of the camera systems, while others provided more anecdotal information. The interviews also explored what policies and procedures each transit agency put in place when implementing the new video systems to determine whether and how implementation procedures may have had an impact on safety statistics.

\section{Safety Impacts of Driver Feedback Systems}

Based on the feedback provided by transit agencies that have installed the systems, as well as the data obtained from NTD reports and DriveCam records, video-based driver feedback systems appear to have enhanced transit safety through a reduction in risky driving behaviors and the frequency of collisions and injuries that ultimately result from those risky behaviors at the agencies examined. In some cases, crash rates appear to actually increase slightly immediately after the systems are installed; however, this may be due to the fact that minor crashes that previously went unreported are now being captured and logged at several transit agencies. Such minor collisions result can result in significant property damage - damage that is sometimes difficult to assign to particular drivers. 
A reduction in the number of collisions per million miles traveled of up to 50 percent occurred following implementation of DriveCam at agencies that have had DriveCam in place for at least two years (see Tables 1 and 2). Not all transit agencies profiled experienced clear declines in the number of collisions and passenger injuries following implementation of the systems. However, interviews with officials at each transit agency revealed that all agencies believed the frequency and severity of "scored events" captured by the systems had declined, indicating that transit operators were adapting their driving habits to avoid risky behaviors, even if the agencies had not yet seen quantifiable reductions in crashes and injuries.

These findings are appropriately evaluated in the context of trends in the total number of collisions and injuries on U.S. transit buses reported through the NTD safety and security database. The average number of collisions per million vehicle revenue miles on transit buses nationwide was 4.12 in 2002-2007 before dropping to 1.61 in 2008, then trending slightly upward to 1.73 by 2012 . The sudden drop in collisions apparently is due to a change in NTD reporting requirements between 2007-2008 that adjusted the thresholds required for collisions to be reported. The number of passenger injuries nationwide decreased slightly, from 4.86 per million passenger miles in 2002-2007, to 3.64 in 2008, before trending slightly up to 4.19 in 2012. Of the six transit agencies examined in this study, four implemented video feedback systems after 2008 and would not be impacted by the change in reporting requirements. New Jersey Transit and Pace both implemented the systems in 2007 but continued to see a downward trend in the number of collisions between 2008-2012.

Information provided during in-person meetings with DriveCam, but not included as an exhibit in this study, supports that conclusion, as it shows that the number of monthly "scored events" per event recorder at five transit agency clients declined at a relatively steady pace since the implementation of DriveCam. This indicates that transit operators are changing their behavior because of the DriveCam system and learning to avoid the risky driving behaviors that cause an event to be captured and scored. Other data provided by DriveCam tracks the number of scored events and collisions per active event recorder among DriveCam's transit industry clients from 2009-2011. The number of scored events captured over time declined consistently, with a slightly less consistent downward trend in number of collisions. A reduction in scored events ultimately should lead to an improvement in overall safety, as these risky behaviors are the precursors to more serious crashes and injuries.

The nine transit agencies and contractors using these systems each stated that adoption of the system must include a comprehensive training and coaching component. Most agencies cite the ability to use video footage as a training tool—on both an individual and a group basis-as one of its main benefits. The majority of the transit agencies profiled in this study downplayed the use of DriveCam for disciplinary purposes. However, it appears that agencies experience the best results when they use DriveCam not only to recognize and reward desirable driving behavior, but also to impose discipline to discourage undesirable or risky behavior. 
Based on prior published research as well as interviews conducted with the transit agencies cited earlier, video-based driver feedback systems can be effective at encouraging safer driving in a number of ways:

1. As a group training tool showing peers engaging in risky driving behaviors and for demonstrating good defensive-driving techniques.

2. As an incentive to drive safer due to the awareness that any risky behaviors will be captured on video.

3. As an individual training tool to help transit managers identify and correct chronic risky driving behaviors that eventually will lead to crashes and injuries.

4. As a means to observe clear traffic code or transit policy violations committed by operators, such as running a red light, not wearing a seatbelt, or using a personal electronic device, leading to disciplinary measures.

5. By providing the indisputable context of an event-difficult to argue against because the cause is clear.

Although there is an upfront capital cost and ongoing operation and maintenance costs associated with implementing video-based driver feedback systems such as DriveCam and SmartDrive, the nine transit agency officials interviewed in this study were nearly unanimous in their view that, over time, the systems would more than pay for themselves through reduced costs and claims associated with crashes and injuries. However, none of the agencies could provide a specific calculation of return on investment.

\section{Addressing Privacy Concerns}

One challenge to implementing video-based driver feedback systems is the perception, particularly by transit operators and the unions that represent them, that installing such systems is an invasion of privacy. However, the fact that these systems are event-triggered and not continuous recordings actually makes them much less intrusive than any system that records continuously. While there are many other types of video surveillance systems found in banks, hotels, department stores, and countless other public places, including security cameras on transit buses, they are designed to record all activities. Because DriveCam and Smart Drive are event-triggered, video cannot be viewed real-time by transit managers and cannot be randomly inspected; it must be triggered by a potentially risky event or manually by the transit operator. This arguably offers transit operators a greater degree of privacy than video surveillance systems used in most other settings.

In the transit industry, managers cannot constantly monitor each bus operator in the field. Before implementing video-based driver feedback systems, transit agencies used ride-alongs by administrative staff or "mystery rider" programs to observe transit operators. However, at most transit agencies, the number of staff assigned to observe transit operators is dwarfed by the number of transit operators. This is also very expensive for operators. As a result, ride-alongs typically occur only with transit operators who already have been singled out by passenger complaints for risky behaviors, and there is very little random monitoring for potentially risky behaviors. Transit operators already work in a very public setting, so it is difficult to understand the argument that these systems 
"violate" a transit operator's right to privacy. Any perceived privacy concerns may be outweighed by the public safety benefits of video-based driver feedback systems.

\section{Impacts on Risk Management}

One of the benefits of video-based driver feedback systems frequently touted by manufacturers is their ability to reduce claim costs by exonerating operators in the case of a collision or other incident that results in a driver or passenger injury. The previously-cited TRB report observes that, "In situations of litigation, the data could be used to exonerate or lessen the liability of drivers. Unfortunately, event-data recorders could also be a liability threat to commercial drivers and their companies in at-fault crash situations, and this perceived vulnerability has limited the use of event-data recorders by commercial fleets" (Knipling et al. 2003, 29).

Transit officials currently using video-based driver feedback systems stated that the systems have been very useful in combating fraudulent claims and exonerating transit operators after collisions. There was general consensus among those interviewed that, at least thus far, footage from the systems has helped dismiss claims, fight traffic tickets, and reduce liability more often than it has posed a liability to transit agencies. Several officials noted that even if the video footage showed the transit agency was at fault, they would rather have all the facts up front and settle at-fault situations quickly rather than pay crash reconstruction and legal fees to fight it out in court, which sometimes can drag on for years and cost millions of dollars.

\section{Conclusions}

Based on interviews with six public transit agencies and three private transit contractors and review of the quantitative data currently available, it appears that video-based driver feedback systems are a promising addition to the transit industry's arsenal of potential safety measures. Further quantitative analysis still is necessary to determine the long-term impact of these systems on collisions and passenger injuries in transit buses. However, the transit agencies that have implemented them have shown that onboard video feedback systems can serve as valuable training tools that provide real-world examples of both desirable and risky driving behaviors, and prior research has shown the systems to be highly effective in other domains such as young drivers and commercial fleet drivers (McGehee et al. 2007, Carney et al. 2010, Simons-Morton et al. 2013, Hanowski et al. 2010). The systems seem particularly effective at reducing the risky driving behaviors that act as precursors to an incident. Based on academic research regarding the use of on-board video systems in behavior-based safety programs in the trucking and motorcoach industries, as well as the experiences of public transit agencies that have implemented the systems, a number of best practices have emerged:

1. Simply installing cameras is not enough. On-board camera systems are most effective when tied to a comprehensive coaching and training program that recognizes safe driving habits and provides timely coaching to prevent repetition of risky behaviors. This kind of coaching service is part of both DriveCam and SmartDrive subscriptions and thus does not add much cost to an operation. 
2. Transit agencies should ensure there is clear management and union buy-in about how the video systems will be used and who will have access to the footage (chain of custody) and ensure that drivers and union officials understand the primary intent of the system is as a training tool.

3. Transit agencies should carefully weigh the potential liabilities and benefits of implementing video-based driver feedback systems from a risk management perspective, although there appears to be general consensus based on the interviews conducted that cameras generally have reduced transit agency liability where they have been implemented, rather than increased it.

Public transit agencies should consider investing in video-based driver feedback systems as one component of an overall safety and training program. However, additional research needs to be conducted to better quantify the long-term impact on crash and injury rates, as well as the return on investment transit agencies have seen due to reductions in claims and insurance premiums.

\section{References}

Carney C., D. V. McGehee, J. D. Lee, M. Reyes, and M. Raby. 2010. Using an event-triggered video intervention system to expand the supervised learning of newly licensed adolescent drivers. American Journal of Public Health 16589.

DriveCam. 2011. DriveCam fleet tracking proven benefits. http://www.drivecam.com/ our-solutions/proven-benefits.

Federal Transit Administration. 2013. Safety and security time series data, National Transit Database. http://www.ntdprogram.gov/ntdprogram/data.htm.

Hanowski, Richard J., and Jeffrey S. Hickman. 2010. Evaluating the safety benefits of a lowcost driving behavior management system in commercial vehicle operations. Washington, DC: Federal Motor Carrier Safety Administration. http://www.fmcsa.dot.gov/ facts-research/research-technology/report/FMCSA-RRR-10-033.pdf.

Hickman, J. S., and E.S. Geller. 2005. Self-Management to increase safe driving among short- haul truck drivers. Journal of Organizational Behavior Management, 23(4): 1-20.

Knipling, Ronald R., Jeffrey S. Hickman, and Gene Bergoffen. 2003. Effective commercial truck and bus safety management techniques: A synthesis of safety practice. Washington, DC: Transportation Research Board. http://onlinepubs.trb.org/onlinepubs/ ctbssp/ctbssp_syn_1.pdf.

Lipsky, Michael. 1980. Street-Level Bureaucracy: Dilemmas of the Individual in Public Services. New York, New York: Russell Sage Foundation.

McGehee, Daniel V., Mireille Raby, Cher Carney, John D. Lee, and Michelle L. Reyes. 2007. Extending parental mentoring using an event-triggered video intervention in rural teen drivers. Journal of Safety Research, 38. National Safety Council. http://www. drivecam.com/uploads/Journal_Safety_Research_lowa_DriveCam.pdf . 
Penn + Schoen Associates, Inc. 1995. User acceptance of Commercial Vehicle Operations (CVO) services; Task B: Critical issues relating to acceptance of CVO services by interstate truck and bus drivers. Final Report, Contract No. DTFH61-94-R-00182. Washington, DC: Federal Highway Administration. http://ntl.bts.gov/lib/jpodocs/ repts_te/714.pdf.

Simons-Morton, Bruce G., C. Raymond Bingham, Marie Claude Ouimet, Anuj K. Pradhan, Rusan Chen, Andrea Barretto, and Jean T. Shope. 2013. The effect on teenage risky driving of feedback from a safety monitoring system: a randomized controlled trial. Journal of Adolescent Health, 53(1): 21-26.

Trucks at Work Blog. 2011. Waving the video wand. http://blog.fleetowner.com/trucks_ at_work/2009/07/14/waving-the-video-wand/.

\section{About the Authors}

MICHAEL LITSCHI (mlitschi@octa.net) currently serves as the Manager of Rail Operations at the Orange County Transportation Authority (OCTA) in California, where he oversees OCTA's investment in the Metrolink commuter rail system and regional passenger rail coordination projects. He earned a bachelor's degree from the University of California, Los Angeles, and a master's degree in Transportation Management from the Mineta Transportation Institute at San José State University. He has worked in the public transportation industry for 11 years.

Peter J. HaAs, Ph.D. (peter.haas@sjsu.edu) is currently the Education Director at the Mineta Transportation Institute (MTI) at San Jose State University. He is the author of many transportation-related publications, as well as the co-author of a textbook on policy analysis and program evaluation, Policy Research: Concepts and Cases. He directs a statewide graduate program for MTI that prepares transportation professionals for upper-level management and executive positions throughout the transportation industry. 